http://dx.doi.org/10.18675/1981-8106.vol26.n52.p194-211

\title{
Escolarização e Biopolítica: o discurso pedagógico produzindo a escola
}

\section{Schooling and Biopolitics: the pedagogical discourse producing school}

\section{Escolarización y Biopolítica: el discurso pedagógico produce la escuela}

\author{
Mirele Corrêa' \\ Gicele Maria Cervill \\ 'Universidade Regional de Blumenau, Santa Catarina - Brasil. E-mail: mirele_correa@yahoo.com.br \\ "Universidade Regional de Blumenau, Santa Catarina - Brasil. E-mail: gicele.cervi@gmail.com
}

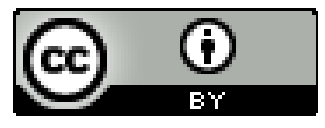

Educação: teoria e prática, Rio Claro, SP, Brasil - eISSN: 1981-8106

Está licenciada sob Licença Creative Common

\section{Resumo}

Este artigo trata de uma pesquisa qualitativa de cunho exploratório, a qual busca problematizar as relações de poder-saber que atravessam o cotidiano escolar e, pensar o presente a partir das noções de governamentalidade e sociedade em tempos de biopolítica. Analisa como os discursos pedagógicos vão produzindo e efetivando a escola, e como por meio dela vem se constituindo outras subjetividades com condições de suportar as exigências desse tempo. Problematiza a escola no tempo presente, reconhece que instituição é esta, como ela está atuando no governo dos indivíduos, valorizando a flexibilidade, a participação, a democracia, a postura de polícia no governo de si e dos outros através de mais escolarização. Os estudos bibliográficos embasados em pensadores como Michel Foucault, Gilles Deleuze, Silvio Gallo, entre outros, e um levantamento cartográfico nos documentos oficiais compõe as procedências desta pesquisa sobre o dispositivo escola. Reconhece que mais escola não é a solução para a resolução dos problemas do mundo, é apenas escolarizar mais. Problematizar a escola também, é pensar em práticas de resistência que possam produzir outras estéticas para os escolares. 
Palavras-chave: Biopolítica. Discurso Pedagógico. Escolarização.

\begin{abstract}
This paper is an exploratory qualitative research, which raises questions about the relations of power-knowledge that cross the school routine and think this from governmentality notions and society in biopolitics times. It examines the pedagogical discourses will produce and effecting the school, and how through it is becoming with other subjectivities able to support the requirements of that time. It questions the school at present, and it recognizes that this institution is, how it is working in the government of individuals, valuing flexibility, participation, democracy, the police attitude in the government of self and others through more schooling. Bibliographic studies grounded in thinkers such as Michel Foucault, Gilles Deleuze, Silvio Gallo, among others. And a mapping in the official documents make up the origins of this research on the school device. Recognizes that more school is no solution to solve the world's problems, only more schooling. Problematize, the school, also is to think of resistance practices that can produce other aesthetic for school.
\end{abstract}

Keywords: Biopolitics. Pedagogic Discourse. Schooling.

\title{
Resumen
}

Este artículo es una investigación cualitativa exploratoria, el cual plantea preguntas acerca de las relaciones de poder-saber que cruzan la rutina escolar y, pensar el presente a partir de las nociones de gubernamentalidad y sociedad en tiempos de Biopolítica. Analiza cómo los discursos pedagógicos producen y construyen la escuela, y cómo se erigen por intermedio de ella otras subjetividades capaces de soportar las exigencias de la época. Cuestiona la escuela en la actualidad, reconoce que esta institución es, cómo está trabajando en el gobierno de las personas, valora la flexibilidad, la participación, la democracia, la actitud de la policía en el gobierno de sí mismo y de los otros a través de una mayor escolaridad. Estudios bibliográficos basados en pensadores como Michel Foucault, Gilles Deleuze, Silvio Gallo, entre otros y un levantamiento cartográfico en los documentos oficiales componen los orígenes de esta investigación en el dispositivo de la escuela. Reconoce que más de la escuela no es la solución para resolver los problemas del mundo, solo una mayor escolaridad. Problematizar la escuela también, es pensar en las prácticas de resistencia que pueden producir otras estéticas para los alumnos.

Palabras clave: Biopolítica. Discurso Pedagógico. Escolaridad. 


\section{Introdução}

A partir do final do século XX, com o início da globalização, intensificaram as críticas sobre a escola, ela passou a ser alvo de elogios e de críticas, porém em nenhum momento deixou de ser considerada instituição fundamental para o desenvolvimento da sociedade. Além disso, passou a ser uma exigência fundamental nos dias de hoje, virou um negócio que busca incluir todos por um tempo cada vez maior. A escola no Brasil, convive com um paradoxo, de um lado é um direito de todos instituído e garantido tanto na Constituição Federal de 1988 (BRASIL, 1988), quanto na Lei de Diretrizes e Bases para a Educação de 9394/96 (BRASIL, 1996), por outro, uma obrigatoriedade imposta sobre todo cidadão. Desse paradoxo, algumas questões emergem, dentre elas: o que está em jogo quando produzimos esta educação? Que relações de poder circulam por este sistema? Como nos tornamos aquilo que somos a partir da escola? Pensar a escola hoje como uma das instituições responsáveis pela constituição do sujeito que a sociedade necessita, produzindo os modos de subjetivação úteis para este tempo - é buscar compreender de onde vieram essas procedências que levaram o conhecimento pedagógico, considerado como arte e ciência, a desempenhar um papel tão importante neste processo escolar.

Diferente de muitos discursos este artigo parte do pressuposto de que a escola mudou muito e continuará modificando para produzir os sujeitos necessários, nesse sentido compreendese que às práticas disciplinares foram incorporadas outras tecnologias que possibilitam à escola na contemporaneidade estar em sintonia com as exigências deste tempo, um tempo de biopolítica. Conforme os estudos realizados, podemos considerar a escola como um instrumento da biopolítica, ou seja, onde o governo regulamenta a população através de um poder exercido sobre todos os aspectos da vida humana. A biopolítica procede por massificação da multiplicidade global, sendo a arte de governar, por meio de procedimentos destinados a dirigir a conduta dos homens (GADELHA, 2009). Desta forma, compreende-se que a escola como dispositivo deste poder não é uma instância fracassada, mas sim uma maquinaria que opera e funciona dentro de um sistema que pretende controlar tudo e todos e produzir o que se quer desde cedo, visto que sem escolarização não suportaríamos as exigências da mesma.

Compreender biopolítica contribui para pensar o que é o indivíduo hoje na sociedade moderna, auxilia a encontrar a procedência do que está em jogo quando produzimos essa escolarização. Este artigo, embasado por estudos bibliográficos e por uma análise cartográfica de alguns documentos oficiais da educação, buscou dialogar com estas problematizações acerca da escolarização nesta sociedade de Biopolítica, tentou compreender que relações de poder estão atuando no surgimento da escola e o que faz com que estes discursos pedagógicos acerca da necessidade da escolarização apareçam, ampliem, permaneçam. 


\section{Biopolítica: uma Explicação Necessária}

O discurso biopolítico começou a ser considerado no final do século XIX e início do século XX. Para compreendermos o que este novo conceito quer explicitar, temos que antes de tudo entender que o tempo histórico, do qual fazemos parte, foi e é constantemente marcado por diversos processos de transformação. Michel Foucault em muitas de suas pesquisas focou seus estudos nos modos de vida marcados pelas sociedades soberana e disciplinar. Contudo, em seus escritos, deixou claro que o tempo da sociedade disciplinar estava acabando, e que Deleuze seria responsável por ilustrar a nova sociedade. Antes que nos atenhamos a estudar essas sociedades, devemos ressaltar que nenhuma sociedade acaba, extingue-se, some. As sociedades se reinventam e se complementam. Por mais que se modernizam, as marcas de cada uma delas ainda são visíveis e sensíveis (FOUCAULT, 2010).

A sociedade soberana evidencia-se por volta do século XVI. É marcada pelo Rei que sancionava as leis e os súditos que obedeciam. A justiça era feita por sua ordem e palavra, a qual manda executar, matar, todo aquele que infringisse as regras, não havia outro tipo de condenação se não a morte, independente do crime que tivesse sido cometido. A obediência e a moralidade eram internalizadas pelo medo de morrer, já que a morte estava visível aos olhos de todos.

Entretanto, por volta do século XVII e XVIII, na Europa, a justiça penal foi reformulada, apareceu uma nova teoria da lei e do crime, uma nova justificação moral que deu ênfase à humanização e à definição do caráter essencialmente corretivo da pena. A punição deixou o campo da visibilidade e entrou no campo da consciência abstrata, "sua eficácia era atribuída à sua fatalidade, não à sua intensidade visível; "a certeza de ser punido é que deve desviar o homem do crime e não mais o abominável teatro" (FOUCAULT, 2010, p. 14, grifo nosso). O crime passou a ser vergonhoso, e a condenação passou a ser marcada no delinquente como um sinal negativo. $\mathrm{O}$ essencial era procurar corrigir, reeducar. A punição atingia mais a vida que o corpo. Entrou em cena, a prisão, que ostentou medidas de sofrimento físico, ou seja, um castigo incorporal, "pois não é mais o corpo, é a alma. À expiação que tripudia sobre o corpo deve suceder um castigo que atue, profundamente, sobre o coração, o intelecto, a vontade, as disposições" (FOUCAULT, 2010, p. 21).

Mudam-se os objetivos, muda-se a sociedade, para que a punição da alma aconteça são necessárias medidas de disciplinamento, técnicas adequadas de controle do indivíduo. De acordo com Foucault (2010), muitos fatores entraram em questão nos julgamentos, passou-se a avaliar as aspirações, os instintos, as enfermidades que levaram à realização do crime. Milhares de especialistas passaram a fazer parte do sistema penal. A prisão deixou de ser o único espaço de detenção, para dar lugar aos manicômios, hospitais de tratamento etc. O corpo passou a ser uma economia política para afetar a alma e o inconsciente. Alguns desses sistemas de sujeição do corpo foram produzidos pelas instituições escolares. Espaços inicialmente destinados a disciplinar o corpo, a moralizar os indivíduos às regras da sociedade e da religiosidade, a prepará- 
los mentalmente e fisicamente para suportar um sistema de produção, consumo e competitividade, instituído tanto pela burguesia quanto pela Igreja. O aparelho escolar é um dispositivo do que Foucault (2010) vem chamar de biopoder.

A escola moderna foi produzida, idealizada e funcionou na sociedade disciplinar e por centenas de anos suas práticas foram voltadas para a produção de um corpo dócil politicamente e útil economicamente. Todavia, como dissemos acima, a sociedade mudou, reformulou-se. Não estamos mais vivendo numa sociedade disciplinar. Por meio dos estudos concernentes ao biopoder, Deleuze (1992) evidencia esta como uma sociedade de controle, na qual Foucault (1999) chamaria de "biopolítica" da espécie humana.

É certo que entramos em sociedades de "controle", que já não são exatamente disciplinares. Foucault é com freqüência considerado como o pensador das sociedades de disciplina, e de sua técnica principal, o confinamento (não só o hospital e a prisão, mas a escola, a fábrica, a caserna). Porém, de fato, ele é um dos primeiros a dizer que as sociedades disciplinares são aquilo que estamos deixando para trás, o que já não somos. Estamos entrando nas sociedades de controle, que funcionam não mais por confinamento, mas por controle contínuo e comunicação instantânea (DELEUZE, 1992, p. 215).

Biopolítica, como nomeia Foucault (1999), caracteriza-se por um governo que regulamenta a população através de um poder exercido sobre todos os aspectos da vida humana, ou seja, o biopoder, gerando uma nova tecnologia política de dominação que se aplica aos corpos numeráveis que se constituem como problema econômico, político e social.

Deleuze (1992) afirma que Foucault situou as sociedades disciplinares nos séculos XVIII e XIX, procedendo-as aos grandes meios de confinamento, analisou muito bem esse projeto visível especialmente na fábrica: concentrar; distribuir no espaço; ordenar no tempo; compor uma força produtiva. Entretanto, Foucault era ciente da transição deste modelo social, que sucedia a sociedade de soberania, e era ciente de que a sociedade disciplinar também iria transitar:

[...] as disciplinas, por sua vez, também conheceriam uma crise, em favor de novas formas que se instalavam lentamente e que se precipitariam depois da Segunda Guerra mundial: sociedades disciplinares é o que já não éramos mais, o que deixávamos de ser (DELEUZE, 1992, p. 220).

Tudo passa a entrar em crise, a sofrer mudanças necessárias. Para Deleuze (1992) instalase uma nova força, na qual a sociedade de controle passa a substituir a disciplinar. Uma não é 
melhor ou pior do que a outra, pois todas elas enfrentam as liberações e as sujeições (DELEUZE, 1992). Na sociedade soberana tirava-se a vida, na disciplinar deixava-se viver para ser exemplo, na sociedade de controle interessa fazer viver, todos devem tolerar e dar chance. Todos devem participar, estar em constante movimento, num processo contínuo e permanente de atualização. A sociedade de controle pretende a todos controlar, de maneira que esse poder não possa ser visível, tudo anda ligeiramente, o tempo corre, não há tempo para reflexão, questionamento, são compromissos, trabalho, estudo, e nesse meio tempo o sistema flui continuamente. Esta sociedade globalizada, informatizada é o resultado de uma mutação do capitalismo que "já não é mais um capitalismo dirigido para a produção, mas para o produto, isto, é, para a venda ou para o mercado. Por isso ele é essencialmente dispersivo, e a fábrica cedeu lugar à empresa"(DELEUZE, 1992, p. 223-224).

A obrigatoriedade da escola, a necessidade de emprego, a moda, o lazer, a constituição de família, a necessidade religiosa, o Senso, o SUS, o Bolsa Família, o IDEB, e tantos outros programas políticos são dispositivos de controle que buscam a manipulação conforme os interesses, e no caso dessa sociedade, o interesse está voltado para o capitalismo, o lucro e o consumo, as principais peças que fazem funcionar este grande sistema.

A biopolítica trata de mecanismos reguladores da população, na tentativa de fixar um equilíbrio, de otimizar. A biopolítica atua com um poder contínuo sobre os indivíduos, é um poder que faz viver (FOUCAULT, 1999). Esse poder garante a vida, garante a segurança, garante a saúde, garante os direitos. Contudo, estamos sempre sob controle, uma vez que estamos sempre e cada vez mais escolarizados.

\section{Cartografando: a Escola em Tempos de Biopolítica}

\subsection{Controlando}

No item anterior, destacamos que estamos vivenciando uma escolarização em tempos de Biopolítica. A escola é mais um dispositivo dessa maquinaria, desse sistema político-econômico que rege as relações mundiais e sociais, que faz esse sistema funcionar sempre, cada vez mais e melhor, porque age diretamente no controle dos indivíduos, de seus corpos, de suas mentes, de suas vidas, regulando, governando. Por meio de uma análise cartográfica nos documentos oficiais da educação nacional, buscamos problematizar esta instituição e compreender como ela está atuando nessa sociedade.

A partir do momento que foi criado uma categoria de infância que precisava ser educada e moralizada, a obrigatoriedade e a necessidade da escola tornou-se fator preponderante. As leis que regulamentam a existência da escola, assim como na sociedade disciplinar também, caracterizam-se por uma rede de hierarquia de caráter mandatório. A tabela abaixo ilustra 
algumas das leis vigentes hoje, que mesmo estabelecendo uma iniciativa livre e autônoma para as escolas, regulamentam seu funcionamento, estabelecendo caminhos a serem seguidos, como é o caso dos Parâmetros (BRASIL, 1997) e das Diretrizes (BRASIL, 1996).

Tabela 1- Leis Vigentes para a Educação na Sociedade Atual

\begin{tabular}{|c|c|c|}
\hline Ano & \multicolumn{2}{|c|}{$\begin{array}{c}\text { Leis Vigentes para a Educação na Sociedade Atual Organizadas } \\
\text { Hierarquicamente }\end{array}$} \\
\hline 1988 & $\begin{array}{l}\text { Constituição da República Federativa } \\
\text { do Brasil }\end{array}$ & $\begin{array}{l}\text { Estabelece a Organização da Educação } \\
\text { Nacional }\end{array}$ \\
\hline 1990 & Lei $\mathrm{N}^{\circ} 8.069$ & $\begin{array}{l}\text { Dispõe sobre o Estatuto da Criança e do } \\
\text { Adolescente e dá outras providências }\end{array}$ \\
\hline 1996 & Lei de Diretrizes e Bases 9.394 & $\begin{array}{c}\text { Estabelece as Diretrizes e Bases da Educação } \\
\text { Nacional }\end{array}$ \\
\hline 1997 & Parâmetros Curriculares Nacionais & Define o Ensino de primeira à quarta série \\
\hline 1998 & Resolução CEB Nº 02 & $\begin{array}{l}\text { Institui as Diretrizes Curriculares Nacionais } \\
\text { para o Ensino Fundamental }\end{array}$ \\
\hline 1998 & Resolução CEB No 03 & $\begin{array}{l}\text { Institui as Diretrizes Curriculares Nacionais } \\
\text { para o Ensino Médio }\end{array}$ \\
\hline 1999 & Resolução CEB Nº 01 & $\begin{array}{l}\text { Institui as Diretrizes Curriculares Nacionais } \\
\text { para a Educação Infantil }\end{array}$ \\
\hline 2009 & Resolução CEB No 05 & $\begin{array}{l}\text { Fixa as Diretrizes Curriculares Nacionais para } \\
\text { a Educação Infantil }\end{array}$ \\
\hline 2010 & Resolução CEB Nº 04 & $\begin{array}{l}\text { Define as Diretrizes Curriculares Gerais para a } \\
\text { Educação Básica }\end{array}$ \\
\hline 2012 & Resolução CEB Nº 06 & $\begin{array}{c}\text { Define as Diretrizes Curriculares Nacionais } \\
\text { para a Educação Profissional Técnica de Nível } \\
\text { Médio }\end{array}$ \\
\hline 2014 & Lei $N^{\circ} 13.005 / 2014$ & $\begin{array}{l}\text { Aprova o Plano Nacional de Educação (PNE), } \\
\text { com metas a serem alcançadas até } 2024\end{array}$ \\
\hline
\end{tabular}

Fonte: Tabela produzida pelas autoras. 
E tem por objetivos:

I - sistematizar os princípios e as diretrizes gerais da Educação Básica contidos na Constituição, na Lei de Diretrizes e Bases da Educação Nacional (LDB) e demais dispositivos legais, traduzindo-os em orientações que contribuam para assegurar a formação básica comum nacional, tendo como foco os sujeitos que dão vida ao currículo e à escola;

II - estimular a reflexão crítica e propositiva que deve subsidiar a formulação, a execução e a avaliação do projeto político-pedagógico da escola de Educação Básica;

III - orientar os cursos de formação inicial e continuada de docentes e demais

profissionais da Educação Básica, os sistemas educativos dos diferentes entes federados e as escolas que os integram, indistintamente da rede a que pertençam (BRASIL, 2010a,grifo nosso).

Apesar de se apresentarem como diretrizes, direções, possíveis caminhos, na prática elas possuem um caráter mandatório, regulando suas ações. Como supramencionado, os verbos que aparecem nos seus objetivos, permitem que o profissional possa fazer suas escolhas de forma mais aberta e autônoma, funcionando como um indicativo de caminhos a serem possivelmente percorridos. É por isso que as diretrizes combinam com esse tempo, com esta sociedade, pois ela faz pensar ser democrático e livre, permitindo diversas possibilidades. Ao mesmo instante, em que ela parece e em certo sentido "abre" para as possibilidades, vem as avaliações que regulam e limitam as possibilidades de invenção. Contudo, ao pensarmos que os conteúdos a serem transmitidos estão sempre ligados aos sistemas de avaliação como as famosas "Provas Brasil", "ENEM", "ANA" é impensável que se fuja disso, ou seja, estamos sempre amarrados aos objetivos propostos pelos Parâmetros, ora pelas avaliações, ora pelo livro didático que vem de acordo com os PCNs, ora pelas formações que utilizam como referência, dizendo-nos sempre o que devemos fazer, como e por quê fazer.

Queremos aqui deixar claro, que não se trata de fazer uma crítica às avaliações em larga escala, porque uma crítica remeteria à reforma delas, e isso não interessa neste momento, nosso foco é apresentá-las como uma política de regulação das escolas e dos escolares, dentro das modulações do tempo presente. Como afirma Gallo (2006), toda escola do Brasil é uma instituição pertencente ao Estado; é ele que regula, supervisiona e avalia. A escola é constituída por um conjunto de normativas que ao propor um direcionamento acaba estabelecendo limites. A legislação brasileira afirma a flexibilização tanto para as escolas públicas quanto para as privadas, desde que seja uma flexibilização controlada, constatada na LDB 9.394/96 
Art. $7^{\circ} \mathrm{O}$ ensino é livre à iniciativa privada [...]

Art. $8^{\circ}$ Parágrafo $2^{\circ}$ Os sistemas de ensino terão liberdade de organização nos termos desta Lei (BRASIL, 1996).

O sistema nos oferece vários caminhos, no entanto, por algum deles você precisa seguir.

\subsection{Incluindo}

Ao mesmo tempo em que a escola institui direitos para assegurar a sociedade, ela também estabelece deveres, limitando sua liberdade. A última LDB 9.394/96, Título II deixa bem clara a responsabilidade da família na obrigação de manter seus filhos na escola.

Art. $2^{\circ}$ A educação, dever da família e do Estado, inspirada nos princípios de liberdade e nos ideais de solidariedade humana, tem por finalidade pleno desenvolvimento do educando, seu preparo, para o exercício da cidadania e sua qualificação para o trabalho.

Art. $6^{\circ}$ É dever dos pais ou responsáveis efetuar a matrícula dos menores, a partir dos sete anos de idade, no ensino fundamental (BRASIL, 1996).

A escola é colocada como um direito de todos e, por isso, todos devemos nos responsabilizar por ela, por sua existência, cobrar a sua efetividade, sua qualidade, ela funciona para e com a sociedade, assim como prevê a LDB 9.394/96, Título III:

Art $5^{\circ} \mathrm{O}$ acesso ao ensino fundamental é direito público subjetivo, podendo qualquer cidadão, grupo de cidadãos, associação comunitária, organização sindical, entidade de classe ou outra legalmente constituída, e, ainda, o Ministério Público, acionar o Poder Público para exigi-lo (BRASIL, 1996).

É dada à escola uma importância tal, que não podemos "viver" sem passar por ela. É um processo indispensável das nossas vidas. E por acreditarmos no seu benefício e importância por meio dessa sujeição é que exigimos educação para todos. Criança fora da escola é algo impensável nessa sociedade. 
Diferente da escola disciplinar que selecionava quem poderia estudar, a escola da Biopolítica promove o discurso "Escola para Todos", não é somente alguns, mas sim todos na escola, o que justifica vários discursos de inclusão. Para alguns uma possibilidade, para o funcionamento da maquinaria, o controle. O discurso de inclusão está afinado a este tempo.

É inadmissível, em tempos de Biopolítica, que um indivíduo não esteja preparado para enfrentar situações instáveis, estamos num tempo em que parece que precisamos ser indivíduos que saibam trabalhar em grupo, aceitar ideias, que saibam tolerar diferenças. Estamos sendo construídos para uma sociedade de tolerância e competitividade. E por isso a escola se faz cada vez mais eficaz e obrigatória.

Art. $4^{\circ} \mathrm{I}$ - ensino fundamental, obrigatório e gratuito, inclusive para os que a ele não tiveram acesso na idade própria;

II - progressiva extensão da obrigatoriedade e gratuidade ao ensino médio;

IV - atendimento gratuito em creches e pré-escolas às crianças de zero a seis anos de idade (BRASIL, 1996).

Antes mesmo da criação da LDB de 1996, a Constituição Federal de 1988 (Capítulo III, Seção I, Art. 205) já previa a obrigatoriedade de ensino e estabelecia as normas para a Educação, pontuando as responsabilidades e os objetivos da mesma que se voltam para a civilidade e à qualificação para o mercado de trabalho.

Art. 205. A educação, direito de todos e dever do Estado e da família, será promovida e incentivada com a colaboração da sociedade, visando ao pleno desenvolvimento da pessoa, seu preparo para o exercício da cidadania e sua qualificação para o trabalho (BRASIL, 1988, p. 121).

A inclusão de "todos na escola" garante massificação do povo, de forma a mantê-los regulados, supervisionados e avaliados, fabricando mentes dóceis, corpos úteis e participativos, necessários para funcionar de acordo com esse sistema globalizado e exigente.

\subsection{Ampliando}

Vemos nesses tempos um discurso pedagógico em torno da necessidade escolar muito forte em nossa sociedade. Ela está pela mídia, pelas revistas, pelos jornais, pelos noticiários, 
pelos outdoors, pelas propagandas. Este discurso é alvo de críticas, de elogios, de protestos, de preocupações, mas acima de tudo de sua necessidade. Para tudo e para cada um, uma escola. Basta abrir uma revista e se deparar com diversas apelações à educação. Abaixo temos alguns exemplos:

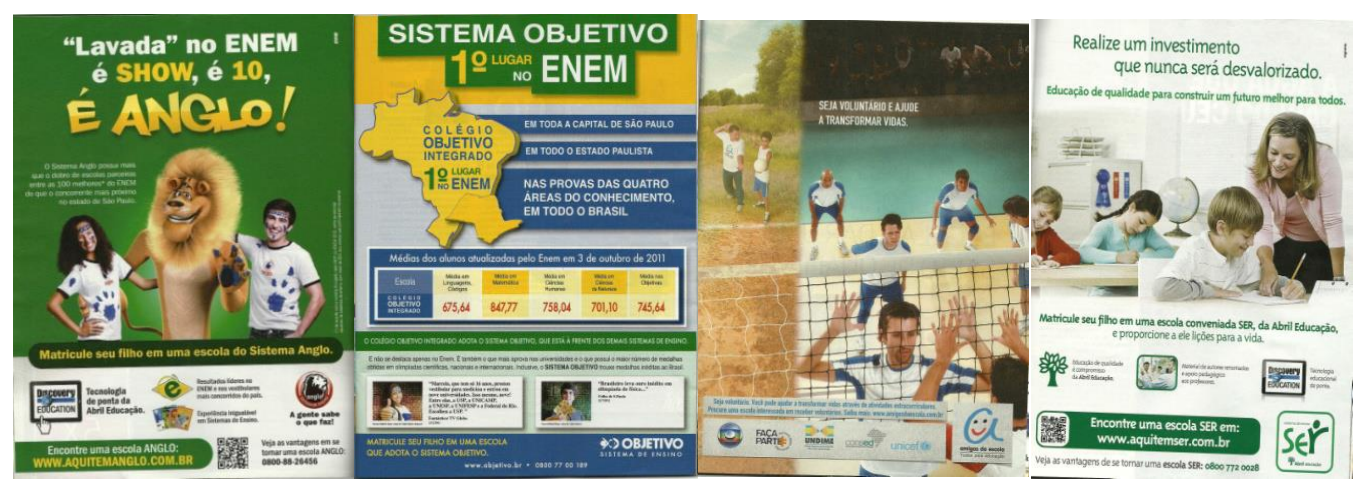

Fonte: REVISTA NOVA ESCOLA (2011) e REVISTA VEJA (2011)

Não basta ter o ensino fundamental, quanto mais escolarização você tiver, mais oportunidades você terá na vida, ou melhor, mais chances de emprego, de crescimento, de riqueza, de consumo, tudo aquilo do que se alimenta o sistema. É o que escutamos de nossos pais, é o que escutamos de nossos professores na escola: "estude se você quiser ser alguém na vida". A escolarização é algo para a vida toda. Busca-se atualização, certificados, enriquecimento do currículo, vantagens, competição. Isso é possível de perceber nas mudanças que sofreram as LDBs, no tocante ao tempo de escolarização.

A primeira LDB 4.024 de 1961, (Título VII, Capítulo I, Art. 38º, Inciso I), estipulava a duração mínima do período escolar de:

a) cento e oitenta dias de trabalho escolar efetivo, não incluído o tempo reservado a provas e exames;

b) vinte e quatro horas semanais de aulas para o ensino de disciplinas e práticas educativas (BRASIL, 1961).

A segunda LDB 5.692 de 1971 ampliou para 90 dias os trabalhos letivos: 
Art. 11. O ano e o semestre letivos, independentemente, do ano civil, terão, no mínimo, 180 e 90 dias de trabalho escolar efetivo, respectivamente, excluído o tempo reservado às provas finais, caso estas sejam adotadas (BRASIL, 1971).

E a última LDB (9.394/96, Capítulo II, Seção I) já estipula uma carga horária ainda maior no tempo de escolarização: “Art. $24^{\circ}$ I - a carga horária mínima anual será de oitocentas horas, distribuídas por um mínimo de duzentos dias de efetivo trabalho escolar, excluído o tempo reservado aos exames finais, quando houver" (BRASIL, 1996). Não obstante, uma nova lei está para ser aprovada no Congresso, a qual pretende ampliar o ano letivo de 200 para 220 dias letivos. O novo Plano Nacional de Educação para o decênio de 2011-2020 propõe metas, as quais ampliam o tempo obrigatório de escolarização, dos 4 aos 17 anos, e o tempo diário em sala de aula, ao oferecer educação em tempo integral em $50 \%$ das escolas públicas de educação básica, o que já está acontecendo. Além disso, promoverá a procura de todos pela escola, de jovens, de adultos, de indígenas, de quilombolas, de infratores, de colonos, de deficientes, incluindo-os na maior parte do tempo nesse processo de subjetivação. É o que mostram alguns dados abaixo, tirados do próprio PNE 2011-2020:

Meta 1: Universalizar, até 2016, o atendimento escolar da população de 4 e 5 anos, e ampliar, até 2020, a oferta de educação infantil de forma a atender a 50\% da população de até 3 anos.

Meta 2: Universalizar o ensino fundamental de nove anos para toda população de 6 a 14 anos[...] (BRASIL, 2010b, p. 3).

O tempo de permanência na escola aumentou evidentemente: a Escola Integral, o Ensino Inovador, a obrigatoriedade de frequentar a educação infantil a partir dos 4 anos são políticas que vão ampliando e efetivando a existência e permanência na escola.

Não estamos discutindo se essa política é boa ou ruim, mas compreender que o que se pretende ao propor mais escolarização, é que os problemas da escola e em especial da aprendizagem sejam resolvidos, assim como os demais imbróglios do país. São os discursos pedagógicos onde tudo passa pela educação. A escola desse tempo passa a assumir todas as responsabilidades da sociedade, ela deve dar conta dos problemas referentes às drogas, ao meio ambiente, à sexualidade, à higiene, à saúde... e, entre tudo isso, a escola deve dar conta ainda das crianças que não aprendem, daquelas com problemas comportamentais, da ausência dos pais, da evasão escolar, do IDEB baixo etc. Para todos esses infortúnios, a solução é agregar todos a maior parte do tempo dentro de salas de aula. É o Programa Mais Escola, são salas multifuncionais, são aulas de apoio, são escolas integrais, são atividades esportivas, clubes de ciência, aulas de reforço, recuperações, mais avaliações, menos reprovações, mais 
medicalizações. Tudo passa pelos muros da escola. O problema é sempre o sujeito, e a solução sempre a escolarização.

\subsection{Regulando}

Na escola da Biopolítica, a repetência já não é mais um instrumento utilizado. Tenta-se, ao contrário, recuperar este aluno de diversas outras maneiras, por meio de recuperações paralelas, exames finais, com o discurso de que é necessário respeitar os diferentes ritmos de aprendizagem. Conforme as Diretrizes Curriculares Nacionais Gerais para a Educação Básica (Res. $\mathrm{N}^{\circ}$ 05/2010),

Art. 20. O respeito aos educandos e a seus tempos mentais, socioemocionais, culturais e identitários é um princípio orientador de toda a ação educativa, sendo responsabilidade dos sistemas a criação de condições para que crianças, adolescentes, jovens e adultos, com sua diversidade, tenham a oportunidade de receber a formação que corresponda à idade própria de percurso escolar (BRASIL, 2010a).

Para os interesses socioeconômicos, a reprovação acaba por estimular a evasão escolar e, por conseguinte, baixar o IDEB, desqualificando o país como potência em desenvolvimento. Todas as formas de avaliação utilizadas pela escola são dispositivos para manter a regulação e as formas de melhorar os resultados internacionais, comprovando o rendimento da população aos níveis socioeconômicos.

Sendo assim, as avaliações também mudam nessa sociedade. Não se avalia somente o conteúdo aprendido individualmente, as avaliações acontecem de diversas formas, é realizado provas com consulta, trabalhos de pesquisa, seminários, provas em dupla, provas de múltipla escolha, provas processuais, o que possibilita a escola manter o estudante em constante processo avaliativo, disponível sempre. Somos treinados e avaliados a todo o momento, a cada etapa de escolarização é necessária uma comprovação, e a escola nos prepara para isso, para que possamos suportar não só todo o controle, como também a vigia de si e dos outros. É para isso que serve o IDEB, o ENEM, a Prova Brasil, a Provinha Brasil, o Vestibular, o ENADE, entre tantos outros exames. A própria LDB 9.394/96 (BRASIL, 1996), Capítulo II, Seção I, Inciso V, comprova isso ao assegurar a avaliação como processo "contínuo e cumulativo do aluno, com prevalência dos aspectos qualitativos sobre os quantitativos e dos resultados ao longo do período sobre os de eventuais provas finais". 
Foucault (1999) explica que as avaliações são mecanismos implantados pela Biopolítica, como forma de regular a vida, assim como a sociedade disciplinar também, possuía seus mecanismos próprios:

Nos mecanismos implantados pela biopolítica, vai se tratar, sobretudo, é claro, de previsões, de estimativas estatísticas, de medições globais; vai se tratar, igualmente, não de modificar tal fenômeno em especial, não tanto tal indivíduo, mas, essencialmente, de intervir no nível daquilo que são as determinações desses fenômenos gerais, desses fenômenos no que eles têm de global [...] (FOUCAULT, 1999, p. 294).

São esses números, que vão colocar cada indivíduo no seu lugar. Há espaço para todos, pois a segurança do território e da população precisa se reafirmar nessas brechas de desigualdade, precisa sempre haver um equilíbrio nesse jogo.

\subsection{Fluindo}

A escola da Biopolítica tenta também, promover todas as formas de democracia. Por meio da valorização da autonomia, da criticidade, do respeito, da tolerância, do trabalho conjunto, algo que antes não era pensado, isto é possível observar nas DCNGEB (Res. Nº 04, Art. 4\%/2010):

I - igualdade de condições para o acesso, inclusão, permanência e sucesso na escola;

II - liberdade de aprender, ensinar, pesquisar e divulgar a cultura, o pensamento, $\mathrm{a}$ arte e o saber;

III - pluralismo de ideias e de concepções pedagógicas;

IV - respeito à liberdade e aos direitos;

[...] VIII - gestão democrática do ensino público, na forma da legislação e das normas dos respectivos sistemas de ensino;(BRASIL, 2010a).

Nessa escola, o professor não é mais visto como superior, conforme os discursos, é visto numa relação horizontal de trocas de aprendizagens e experiências recíprocas, numa relação de igualdade. Os espaços são mais valorizados, não se senta mais enfileirado, e sim em círculos, nos quais todos aprendem a vigiar e todos aceitam ser vigiados, aprendem a ser polícia de si e dos 
outros. Aprende-se a escutar, a falar, faz-se o que se gosta, valoriza-se as construções e acima de tudo o aluno que é o centro da aprendizagem.

Art. $6^{\circ} \mathrm{Na}$ Educação Básica, é necessário considerar as dimensões do educar e do

cuidar, em sua inseparabilidade, buscando recuperar, para a função social desse nível da educação, a sua centralidade, que é o educando, pessoa em formação na sua essência humana (BRASIL, 2010a).

Se fosse para encontrar um slogan perfeito que caracterizasse essa sociedade de Biopolítica, esse seria com certeza: Democracia. Aprende-se desde muito cedo que vivemos em um país democrático, que possuímos a liberdade de expressão. É por meio da democracia que sabemos qual o nosso papel e lugar na sociedade, que aprendemos a participar, que reconhecemos nossos direitos e deveres, que vivemos de forma pacífica, que toleramos as diferenças, que podemos nos pronunciar, exigir e criticar.

Sobre democracia encontra-se nos PCNs, no volume que introduz os Temas Transversais, que

[...] pode ser entendida em um sentido restrito como um regime político. Nessa concepção restrita, a noção de cidadania tem um significado preciso: é entendida como abrangendo exclusivamente os direitos civis (liberdade de ir e vir, de pensamento e expressão, direito à integridade física, liberdade de associação) e os direitos políticos (eleger e ser eleito), sendo que seu exercício se expressa no ato de votar (BRASIL, 1997, p. 19).

Esse governo de si e a consciência democrática, que visa o respeito aos direitos do próximo é uma questão de segurança, porque permite que, na busca do consenso, as pessoas se conformem.

Outro aspecto relevante da escola dessa sociedade é a formação de professores. Com a falta de valorização profissional e os baixos salários, um grande problema enfrentado é a falta de mão de obra. A obrigatoriedade existe para todos, as salas de aula estão cada vez mais cheias, porém não há professores suficientes para dar conta da demanda educacional. Desta forma, diversos programas de governo foram instalados para tentar suprir esta falta. Todos os programas têm o mesmo objetivo: incentivar a educação voltada para o mercado de trabalho. Disso surgem os programas gratuitos para o Ensino Superior voltado para as Licenciaturas, como o PROUNI, o PARFOR, as Bolsas de estudos, as cotas, o incentivo ao magistério. Ainda, programas de baixo 
custo e financiamento que conseguem garantir a vaga do cidadão na universidade, como o FIES, as faculdades a distância. Sem falar em programas de estímulo voltados à meritocracia, como o Prêmio Victor Civita Educador Nota 10, Prêmio Professor Alfabetizador, entre outros.

No Novo Plano Nacional da Educação 2011-2020, uma meta já está elaborada para aumentar o número de integrantes no ensino superior. Afinal, para um país em crescimento, é inadmissível possuir uma porcentagem tão baixa de matriculados: "Meta 12: Elevar a taxa bruta de matrícula na educação superior para $50 \%$ e a taxa líquida para $33 \%$ da população de 18 a 24 anos, assegurando a qualidade da oferta" (BRASIL, 2010b, p. 77). Além da formação inicial superior, o professor, como responsável pela formação de todo indivíduo, precisa estar constantemente sendo formado, revisto, regulado, vigiado. Para garantir que seu trabalho esteja sendo realizado com sucesso, o professor precisa manter-se numa formação continuada, até o final de sua carreira. As leis mostram (Consoante a LDB 9.394/96, Capítulo V, Título VI):

Art. $63^{\circ}$. Os institutos superiores de educação manterão:

I - cursos formadores de profissionais para a educação básica, inclusive o curso normal superior, destinado á formação de docentes para a educação infantil e para as primeiras séries do ensino fundamental;

II - programas de formação pedagógica para portadores de diplomas de educação superior que queiram se dedicar à educação básica;

III - programas de educação continuada para os profissionais de educação dos diversos níveis (BRASIL, 1996, grifo nosso).

Todos mantemos um compromisso social que reafirma à escola seu funcionamento a cada dia. Esses dados indicam possibilidades para pensarmos a escola nessa sociedade, a maneira que ela está instituída, como ela funciona, com qual objetivo.

Não conseguimos trazer todos os documentos, há muitas outras leis e programas interessantes para ilustrar a escola atual, entretanto, estes dados sugerem que esta escola não é mais a mesma. A escola da Biopolítica está mais evidente, mais acelerada, mais ágil, mais exigente, mais flexível, mais inclusiva, mais democrática, mais participativa, está continuada, com mais avaliação, mais dias, mais e sempre mais escola. São os discursos pedagógicos produzindo a escola. Discursos que estão por toda parte. Discursos que não param de reforçar, reafirmar, reformar, na garantia de sempre mais escolas e sempre mais escolares por um tempo sempre maior. Não se trata de fazer a crítica, mas apontar que a escola nesta sociedade opera com outros dispositivos. 


\section{Considerações Finais}

Na escola, no século XXI, em tempos de biopolítica, os discursos pedagógicos não param de produzi-la, eles andam como a serpente: rápidos, rasteiros e contínuos. E a reafirmam a cada dia, produzem a necessidade da mesma, e a fazem funcionar sempre, cada vez mais. Pedagogia e escola se sintonizam para fazer mais escola, porém com a intenção de se dar mais do mesmo. Mais escolarização não garante a aprendizagem, mais escolarização não quer dizer mais cultura e instrução, é apenas mais obediência e ocupação. Talvez o que se tem a fazer seja oferecer outras possibilidades, ampliando o repertório cultural das pessoas. O conhecimento vai muito além , do espaço escolar, da sala de aula. E o aprendizado pode ser concebido como um ato prazeroso aos estudantes e não como uma obrigação ou uma cobrança.

Escapar do mundo que vivenciamos é algo impossível, porque esta sociedade reforçasse a cada dia. Entretanto, nas brechas da democracia é possível encontrar possibilidades. Acredito que esta pesquisa pode servir como um meio de resistência na tarefa de problematizar os discursos pedagógicos e o que eles vêm produzindo, e mais do que isso, é uma forma de instigar a vontade de pensar e fazer uma escola de outro jeito.

\section{Referências}

BRASIL. Lei No 4.024, de 20 de Dezembro de 1961. Fixa as Diretrizes e Bases da Educação Nacional. Diário Oficial da União, Brasília, DF, data.

BRASIL. Constituição da República Federativa do Brasil. Brasília, DF: Senado Federal, de 05 de outubro de 1988.

BRASIL. Lei Federal 9394, de 20 de dezembro de 1996. Estabelece as diretrizes e bases da educação nacional. Diário Oficial da União, Brasília, DF, 23 dez. 1996.

BRASIL. SECRETARIA DE EDUCAÇÃO FUNDAMENTAL. Parâmetros Curriculares Nacionais: introdução aos parâmetros curriculares nacionais. Brasília: MEC/SEF, 1997.

BRASIL. MINISTÉRIO DA EDUCAÇÃO. Diretrizes Curriculares Nacionais Gerais para a Educação Básica. Resolução CNE/CEB 4/2010a. Diário Oficial da União, Brasília, 14 julho 2010. Seção 1, p. 824.

BRASIL. MINISTÉRIO DA EDUCAÇÃO. Plano Nacional da Educação para o decênio de 2011-2020. Brasília: MEC, 2010b. 
DELEUZE, G. Controle e Devir. Futur Antérieur entrevista a Toni Negri. In: DELEUZE, G. Conversações. . Tradução de Peter Pál Pelbart. Rio de Janeiro: Editora 34, 1992. 232 p.

DEZ motivos para se indagar com a corrupção. Revista Veja, São Paulo, ano 44, n.43, 26 out. 2011. Edição 2240.

FOUCAULT, M. Em Defesa da Sociedade: Curso no Collège de France (1975-1976). Tradução Maria Ermantina Galvão. São Paulo: Martins Fontes, 1999. 382 p.

. Vigiar e Punir: Nascimento da Prisão. Tradução de Raquel Ramalhete. 38. ed. Petrópolis, RJ: Vozes, 2010. 291 p.

GADELHA, S. Biopolítica, governamentalidade e educação. Introduções e conexões, a partir de Michel Foucault. Belo Horizonte: Autêntica Editora, 2009.

GALLO, S. Escola Libertária Versus Legislação Autoritária. Revista de cultura libertária, arte e literatura, Cidade, ano 11, n. 45, p. 08-12 2006.

VOCÊ no Centro das Atenções. Revista Nova Escola, Cidade, ano XXVI, n.246, out. 2011.

Recebido em: 11/02/2015

Revisado em: 09/09/2015

Aprovado para publicação em: 07/06/2016

Publicado em: 31/08/2016 